\title{
Partial androgen insensitivity syndrome
}

INSERM

\section{Source}

INSERM. (1999). Orphanet: an online rare disease and orphan drug data base. Partial androgen insensitivity syndrome. ORPHA:90797

Partial androgen insensitivity syndrome (PAIS) is a disorder of sex development (DSD) distinct from complete AIS (CAIS; see this term) characterized by the presence of abnormal genital development in a 46,XY individual with normal testis development and partial responsiveness to age-appropriate levels of androgens. 